\title{
AVALIAÇÃO AMBIENTAL DE ALTERNATIVAS CONSTRUTIVAS DE UM EDIFÍCIO CONTÊINER
}

\section{ENVIRONMENTAL ASSESSMENT OF CONSTRUCTIVE ALTERNATIVES OF A CONTAINER BUILDING}

\author{
Lucas Rosse Caldas ${ }^{1}$ \\ Universidade Federal do Rio de Janeiro, Rio de Janeiro, Rio de Janeiro, Brasil, Irc.ambiental@gmail.com \\ Loyde Vieira de Abreu-Harbich² \\ Universidade Presbiteriana Mackenzie, São Paulo, São Paulo, Brasil, loydeabreu@gmail.com \\ Karla Emmanuela Ribeiro Hora ${ }^{3}$ \\ Universidade Federal de Goiás, Goiânia, Goiás, Brasil, karlaemmanuela@gmail.com
}

\begin{abstract}
Resumo
Contêineres vêm sendo utilizados como edifícios nos últimos anos. Para isto, devem atender requisitos de desempenho térmico obtidos, a depender do clima, com o uso de materiais isolantes e fechamentos adicionais. Assim, o objetivo desse estudo é comparar o desempenho ambiental de um edifício contêiner de uso comercial com diferentes estratégias construtivas da envoltória. A metodologia baseou-se em: (a) definição de alternativas construtivas da envoltória do edifício contêiner; (b) simulações termoenergéticas com auxílio do software DesignBuilder para quatro cidades de diferentes zonas bioclimáticas (ZB) brasileiras: São Paulo (ZB3), Brasília (ZB4), Teresina (ZB7) e Rio de Janeiro (ZB8); (c) Avaliação do Ciclo de Vida (ACV), com escopo do berço ao túmulo, considerando as seguintes categorias de dano: (1) Mudanças Climáticas, (2) Saúde Humana, (3) Qualidade do Ecossistema e (4) Depleção de Recursos. A alternativa construtiva da envoltória composta por drywall e isolante térmico foi a mais vantajosa dentre as avaliadas. A absortância solar das fachadas influenciou significativamente nos resultados, principalmente para as ZB7 e ZB8. A cidade de Teresina foi a que apresentou maior consumo de energia operacional e, consequentemente, maiores impactos ambientais. Ao final, apresentam-se algumas diretrizes ambientais para esta tipologia de projeto.
\end{abstract}

Palavras-chave: Edifícios de contêineres. Avaliação do Ciclo de Vida. Zonas Bioclimáticas.

\begin{abstract}
Containers have been widely used as buildings lately; therefore, they need to meet thermal performance requirements by using, depending on the climate, insulation materials, and additional layers for the enclosure. This study compares the environmental performance of a container building for commercial use with different constructive strategies for the envelope. The methodology was based: (a) definition of the envelope constructive alternatives for the container building; $(b)$ thermal and energy performance simulations with the aid of DesignBuilder software for four cities in different Brazilian bioclimatic zones (ZB): São Paulo (ZB2), Brasilia (ZB4), Teresina (ZB7) and Rio de Janeiro (ZB8); (c) Life Cycle Assessment (LCA), from cradle to grave, considering the following categories of damage: (1) Climate Change, (2) Human Health, (3) Ecosystem Quality and (4) Depletion of Resources. The envelope constructive alternative of drywall and thermal insulation was more advantageous than the others. The thermal absorptance influenced the results, especially for ZB7 and ZB8. The city of Teresina showed the highest operational energy consumption and, consequently, the highest environmental impact. Moreover, environmental guidelines were presented for this type of building.
\end{abstract}

Keywords: Container's buildings. Life Cycle Assessment. Bioclimatic zones.

How to cite this article:

CALDAS, L. R.; ABREU-HARBICH, L. V. DE; HORA, K. E. R. Avaliação ambiental de alternativas construtivas de um edifício contêiner. PARC Pesquisa em Arquitetura e Construção, v. 11, p. e020008, 29 jun. 2020.

DOI:https://doi.org/10.20396/parc.v11i0.8654887 


\section{Introdução}

A construção civil é uma das atividades que mais consome recursos naturais e gera resíduos (UNEP, 2017). Assim, a reutilização, o reaproveitamento, ou a readaptação tanto de materiais descartados quanto de edifícios são necessárias para melhorar a sustentabilidade no ambiente construído. O reaproveitamento de contêineres descartados somado à busca por um processo construtivo que gere menos perdas e resíduos tem levado projetistas e clientes a adotarem contêineres ou parte deles em seus projetos. Somente após os contêineres passarem por cortes e processos de tratamento, como pintura especial para proteção contra intempéries e incêndio, isolamento térmico e acústico e, em alguns casos, reforço mecânico, é possível o seu reaproveitamento (GARRIDO, 2015). No Brasil, o uso de contêineres como edifício começou como instalações provisórias de canteiros de obras, como banheiros e escritórios e, posteriormente, em habitações e comércio - restaurantes, escritórios e lojas, conforme a Figura 1.

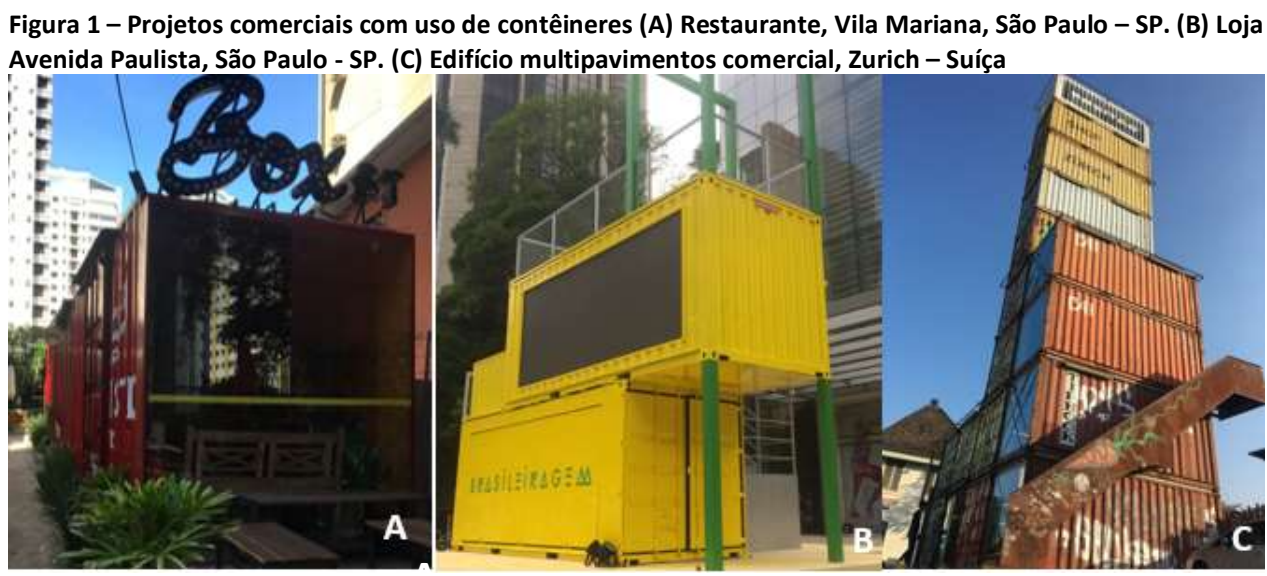

Fonte: Os autores.

A vida útil de um contêiner é de 10 a 20 anos (CARBONARI; BARTH, 2015). Cerca de vinte milhões de contêineres ISO ${ }^{(1)}$ circulam pelo mundo, sendo que $5 \%$ deste total são descartados anualmente (WORLD SHIPPING COUNCIL, 2014). No final da vida útil, os contêineres se acumulam nas regiões portuárias devido à inviabilidade de retorná-los vazios para os lugares onde foram produzidos (ISLAM et al., 2016). Logo, o Brasil possui um grande potencial para a reutilização de contêineres na construção civil, pois existem 37 portos públicos.

A maioria dos estudos sobre o desempenho ambiental de contêineres utilizados como edificação abordam os parâmetros de projeto, tais como: dimensões existentes no mercado, espessura da parede, tipos de cobertura e fechamentos; importantes para a definição de alternativas construtivas avaliadas neste estudo. Romano, Paris e Neuenfeldt Júnior (2014) discutem a importância da reutilização de contêineres no setor de edificações, mas não chegam a quantificar como essa reutilização pode trazer impactos ambientais positivos. Carbonari e Barth (2015) investigam os principais aspectos construtivos necessários para a reutilização de contêineres em três edificações comerciais, localizadas na região sul do Brasil, entre eles: transporte e logística, fundações, abertura para portas e janelas, materiais de fechamento e revestimento para envoltória e instalações elétricas e hidrossanitárias.

Lopes (2016) comparou um contêiner composto por divisórias internas em drywall e fechamento externo em placas cimentícias com um sistema construtivo em alvenaria, observando que o edifício de contêiner se mostrou mais vantajoso, com menor 
consumo de energia para refrigeração. Para melhoria do desempenho térmico de uma casa contêiner em três zonas bioclimáticas brasileiras (2, 3 e 8), Souza, Viana e Gomes (2019) observaram a necessidade do emprego de isolamento térmico nos fechamentos verticais, uma cobertura termicamente eficiente e o uso de cores claras no fechamento externo.

Islam et al. (2016) e Song, Mithraratne e Zhang (2016), por sua vez, utilizaram a Avaliação do Ciclo de Vida (ACV) para avaliar o desempenho ambiental de casas de contêineres. Ambos os estudos concluíram que o contêiner pode ser usado como material de construção com benefícios ambientais devido à menor massa da edificação e ao potencial de reciclagem de contêineres. Já Atmaca e Atmaca (2016) verificaram que as casas contêineres são piores em termos de consumo de energia que uma casa préfabricada de concreto na Turquia, quando o ciclo de vida é considerado. Os autores utilizaram as metodologias de Avaliação do Ciclo de Vida Energética (ACVE) e Avaliação do Custo do Ciclo de Vida (ACCV) e concluíram que as casas pré-fabricadas têm um consumo de energia e custos do ciclo de vida $25,1 \%$ e $29,7 \%$ menores que as casas containers, respectivamente.

A ACV se apresenta como uma metodologia bastante útil para avaliar o desempenho ambiental de contêineres, como apontam Islam et al. (2016) e Song, Mithraratne e Zhang (2016). Através da ACV é possível quantificar os potenciais impactos ambientais envolvidos nas etapas de produção, construção uso e fim de vida, bem como os impactos evitados relacionados à reutilização do contêiner.

Essa pesquisa tem como objetivo geral analisar o desempenho ambiental de um edifício contêiner de uso comercial com diferentes estratégias construtivas da envoltória. Os objetivos específicos são: (1) avaliar o desempenho ambiental para diferentes zonas bioclimáticas brasileiras; (2) comparar as alternativas construtivas com um sistema de alvenaria estrutural de blocos de concreto; (3) identificar a alternativa construtiva de contêiner com maior potencial de utilização em cada zona bioclimática; (4) desenvolver diretrizes ambientais para projetos de edifícios de contêiner.

\section{Método}

O procedimento metodológico adotado foi: (a) seleção das zonas climáticas a serem avaliadas; (b) caracterização do edifício e alternativas construtivas; (c) simulações termoenergéticas; (d) avaliação do ciclo de vida.

Neste estudo foram selecionadas quatro cidades de diferentes zonas bioclimáticas (ZB) brasileiras: São Paulo (ZB3), Brasília (ZB4), Teresina (ZB7) e Rio de Janeiro (ZB8). O critério de escolha foi a localização geográfica e climática (diferentes regiões brasileiras e climas distintos) e maior potencial de aplicabilidade (capitais estaduais).

\section{Caracterização do edifício e alternativas construtivas}

O projeto selecionado para avalição é do tipo comercial para atividade de escritório com área de $28,15 \mathrm{~m}^{2}$ e envoltória composta por um contêiner de carga tipo ISO de aço High Cube (40') de dimensões 12,03 m x 2,34 m x 2,71 m (comprimento x largura x altura) e espessura de 2,6 mm. Embora a espessura das fachadas varie de acordo com as soluções construtivas, a edificação foi modelada para que todas as alternativas possuíssem a mesma área útil de piso. A edificação possui duas janelas, voltadas para orientação oeste, de dimensões de 2,40 m x 1,20 m, com vidro incolor monolítico de $6 \mathrm{~mm}$ (fator solar de $84 \%$ e transmitância térmica de $5,60 \mathrm{~W} / \mathrm{m}^{2} . \mathrm{K}$ ) e uma porta de alumínio com duas folhas (transmitância térmica de $5,70 \mathrm{~W} / \mathrm{m}^{2} . \mathrm{K}$ ). Foi adotada como cobertura telha sanduíche termoacústica (transmitância térmica de $0,60 \mathrm{~W} / \mathrm{m}^{2} . \mathrm{K}$ ) e piso de madeira com 
revestimento de laminado de madeira. Para a fundação indicou-se um radier de concreto armado de $12 \mathrm{~cm}$.

Foram comparadas as seguintes alternativas construtivas: $(P 1)$ somente o contêiner; $\left(\mathrm{P}_{2}\right)$ drywall interno com isolante térmico; ( $\left.\mathrm{P}_{3}\right)$ fechamento externo com placas cimentícias; (P4) fechamento externo com placas cimentícias e drywall internamente com isolante térmico; $\left(\mathrm{P}_{5}\right)$ sistema de alvenaria estrutural com blocos de concreto e revestimento de argamassa (Figura 2).

Foram considerados os seguintes valores de absortância das fachadas: 0,3, 0,6 e 0,9. A transmitância térmica e capacidade térmica foram calculadas com base na NBR 15220-2 (ABNT, 2005), apresentadas na Tabela 1.

Figura 2 - Alternativas construtivas avaliadas

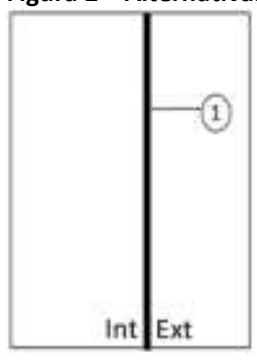

P1

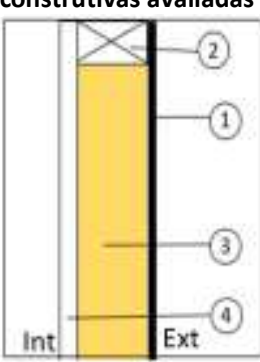

P2

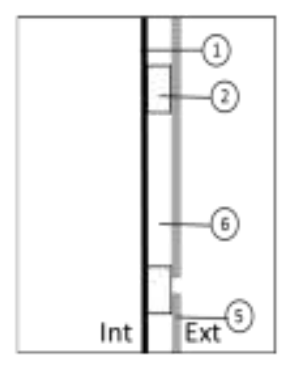

P3

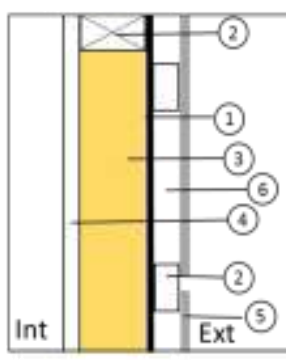

P4

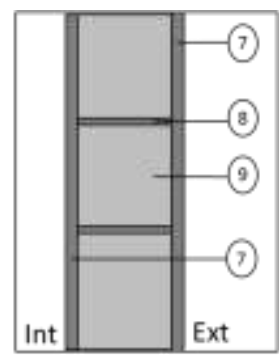

P5

\begin{tabular}{|c|c|c|}
\hline \multicolumn{3}{|l|}{ LEGENDA } \\
\hline (1) Aço container & (2) Perfil de aço (3) Lă de rocha/ar (4) Placa de gesso & Placa cimentícia \\
\hline (6) $\mathrm{Ar}$ & 7) Revestimento argamassado & Bloco de concreto \\
\hline Int -Interior da e & 1̧̧ão Ext-Exterior da edificação & \\
\hline
\end{tabular}

Fonte: Os autores.

Tabela 1 -Dados das alternativas construtivas avaliadas

\begin{tabular}{|c|c|c|c|}
\hline Alternativas & Descrição & $\begin{array}{l}\text { Transmitância } \\
\text { térmica }\left(\mathrm{W} / \mathrm{m}^{2} . \mathrm{K}\right)\end{array}$ & $\begin{array}{c}\text { Capacidade } \\
\text { térmica } \\
\left(\mathrm{kJ} / \mathrm{m}^{2} . \mathrm{K}\right)\end{array}$ \\
\hline P1 & Aço $(2,6 \mathrm{~mm})$ e pintura. & 5,9 & 14,4 \\
\hline P2 & $\begin{array}{l}\text { Aço }(2,6 \mathrm{~mm}) \text {, lã de rocha }(50 \mathrm{~mm}) \text { chapa de gesso }(12,7 \mathrm{~mm}) \text { e tinta }(1 \\
\mathrm{mm}) .\end{array}$ & 0,8 & 28,4 \\
\hline P3 & $\begin{array}{l}\text { Placa cimentícia }(10 \mathrm{~mm}) \text {, estrutura metálica }(90 \mathrm{~mm}), \text { Aço }(2,6 \mathrm{~mm}) \text { e } \\
\text { tinta }(1 \mathrm{~mm}) \text {. }\end{array}$ & 2,9 & 30,3 \\
\hline P4 & $\begin{array}{l}\text { Placa cimentícia }(10 \mathrm{~mm}) \text {, estrutura metálica }(50 \mathrm{~mm}) \text {, aço }(2,6 \mathrm{~mm}) \text {, lã } \\
\text { de rocha }(50 \mathrm{~mm}) \text { placa de gesso }(12,7 \mathrm{~mm}) \text { e tinta }(1 \mathrm{~mm}) .\end{array}$ & 0,7 & 44,3 \\
\hline P5 & $\begin{array}{l}\text { Blocos estruturais de concreto (140 mm), chapisco }(5 \mathrm{~mm}) \text {, camada única } \\
\qquad(20 \mathrm{~mm}) \text { e tinta }(1 \mathrm{~mm}) .\end{array}$ & 2,7 & 272,0 \\
\hline
\end{tabular}

Fonte: Os autores.

\section{Simulação termoenergética}

As simulações computacionais foram realizadas no software DesignBuilder. Os dados climáticos utilizados para as quatro zonas bioclimáticas selecionadas foram obtidos no Laboratório de Eficiência Energética de Edificações de Santa Catarina (LabEEE, 2019). A edificação foi modelada e simulada sem a consideração do seu entorno (por exemplo, edificações vizinhas, vegetação e etc.).

O equipamento de ar condicionado (do tipo Split) foi selecionado por funcionar durante todo o período de ocupação da edificação considerando a agenda (Schedule) de $8 \mathrm{~h}$ às $17 \mathrm{~h}$, de segunda a sexta feira, caso atinja uma temperatura superior à de setpoint do ambiente. A temperatura de setpoint definida para cada zona bioclimática foi $23,7{ }^{\circ} \mathrm{C}$ para São Paulo, $24,3{ }^{\circ} \mathrm{C}$ para Brasília, $26,3{ }^{\circ} \mathrm{C}$ para Teresina e $24,9{ }^{\circ} \mathrm{C}$ para Rio de Janeiro, 
as mesmas adotadas por Pereira e Assis (2010) e Caldas, Lira e Sposto (2017). Adotou-se o Coeficiente de Performance (CoP) do aparelho de 3,2 W/W, sendo o valor mínimo dos equipamentos classificados como A na Etiqueta Nacional de Conservação de Energia (ENCE) do PROCEL (ELETROBRAS, 2014).

O edifício foi simulado para 8760 horas. A carga térmica interna considerada foi de 32,6 $\mathrm{W} / \mathrm{m}^{2}$ (ocupação da edificação por três usuários - $345 \mathrm{~W}$; iluminação com lâmpadas fluorescentes - $448 \mathrm{~W}$-; três computadores e uma impressora - $125 \mathrm{~W}$ ).

Avaliou-se, na análise de resultados, o consumo anual de energia elétrica para climatização (em $\mathrm{kWh} / \mathrm{m}^{2}$. ano), sendo considerado apenas o resfriamento do edifício (Tabela 2).

\begin{tabular}{|c|c|c|c|c|c|}
\hline Alternativas construtivas & $\begin{array}{l}\text { Absortância fachada } \\
\text { externa }\end{array}$ & $\begin{array}{l}\text { São Paulo } \\
\text { (kWh/m². } \\
\text { ano) }\end{array}$ & $\begin{array}{c}\text { Brasília } \\
\text { (kWh/ } \mathrm{m}^{2} \\
\text { ano) }\end{array}$ & $\begin{array}{l}\text { Teresina } \\
\text { (kWh/ } \mathrm{m}^{2} \\
\text { ano) }\end{array}$ & $\begin{array}{l}\text { Rio de Janeiro } \\
\text { (kWh/ } \mathrm{m}^{2} \text {. } \\
\text { ano) }\end{array}$ \\
\hline \multirow{3}{*}{$\begin{array}{c}\text { P1 - Contêiner sem fechamentos } \\
\text { adicionais }\end{array}$} & 0,3 & 60,50 & 83,88 & 277,20 & 140,56 \\
\hline & 0,6 & 98,25 & 132,50 & 353,10 & 193,31 \\
\hline & 0,9 & 142,32 & 187,72 & 431,50 & 249,17 \\
\hline \multirow{3}{*}{$\begin{array}{c}\text { P2 - Drywall interno com isolante } \\
\text { térmico }\end{array}$} & 0,3 & 61,46 & 85,37 & 216,13 & 124,59 \\
\hline & 0,6 & 68,17 & 93,50 & 227,42 & 133,13 \\
\hline & 0,9 & 74,76 & 101,52 & 238,31 & 141,37 \\
\hline \multirow{3}{*}{$\begin{array}{c}\text { P3 - Fechamento externo com placas } \\
\text { cimentícias }\end{array}$} & 0,3 & 55,54 & 78,22 & 233,94 & 124,58 \\
\hline & 0,6 & 75,66 & 103,68 & 272,06 & 152,05 \\
\hline & 0,9 & 96,99 & 130,15 & 309,47 & 179,34 \\
\hline \multirow{3}{*}{$\begin{array}{c}\text { P4 - Fechamento externo com placas } \\
\text { cimentícias e drywall internamente com } \\
\text { isolante térmico }\end{array}$} & 0,3 & 57,31 & 80,38 & 207,16 & 118,02 \\
\hline & 0,6 & 63,10 & 87,40 & 217,13 & 125,54 \\
\hline & 0,9 & 68,71 & 94,23 & 226,43 & 132,55 \\
\hline \multirow{3}{*}{$\begin{array}{l}\text { P5 - Alvenaria estrutural com blocos de } \\
\text { concreto }\end{array}$} & 0,3 & 33,63 & 49,87 & 200,11 & 95,82 \\
\hline & 0,6 & 47,46 & 68,91 & 234,15 & 118,30 \\
\hline & 0,9 & 62,91 & 89,74 & 268,49 & 141,60 \\
\hline
\end{tabular}

Fonte: Os autores.

\section{Avaliação do Ciclo de Vida (ACV)}

Conforme NBR ISO 14040 (ABNT, 2009), a ACV é dividida em quatro etapas: (1) Definição do objetivo e escopo; (2) Inventário do ciclo de vida; (3) Avaliação dos impactos do ciclo de vida; (4) Interpretação. As três primeiras etapas estão detalhadas a seguir e a última no item de "Resultados e Discussão".

Definição do escopo e unidade funcional

O escopo consistiu na produção dos materiais e componentes utilizados no edifício, transporte, reposição, energia operacional do edifício, demolição/desconstrução, transporte e destinação final (Figuras 3 e 4).

Foi avaliado um edifício de contêiner com vida útil de 50 anos, conforme a NBR 15575 (ABNT, 2013). Para isto, considerou-se, somente, os sistemas de vedações verticais utilizados na fachada do edifício. Embora as vedações avaliadas apresentem desempenho térmico diferente, a unidade funcional escolhida garante equivalência funcional uma vez que a temperatura interna desse edifício de contêiner é equivalente aos setpoints determinados para todas as alternativas de acordo com cada zona bioclimática.

Para a avaliação dos impactos evitados foi utilizado o método de "Reciclagem no Fim de Vida" (WORLDSTEEL ASSOCIATION, 2011), em que os benefícios são atribuídos para a produção do material reaproveitado devido à produção de material primário. Ou seja, o reaproveitamento do contêiner para a construção de paredes de uma nova edificação 
evita a construção de paredes do material primário no futuro. O material reciclado consumido não traz consigo os impactos ambientais do material primário (produção do contêiner utilizado no transporte). Presume-se que o material reciclado seja usado como entrada de um novo processo e não pode ser usado em outra aplicação (SCHRIJVERS; LOUBET; SONNEMANN, 2016).

Figura 3 - Escopo avaliado para o edifício em contêiner, considerando a alternativa P4

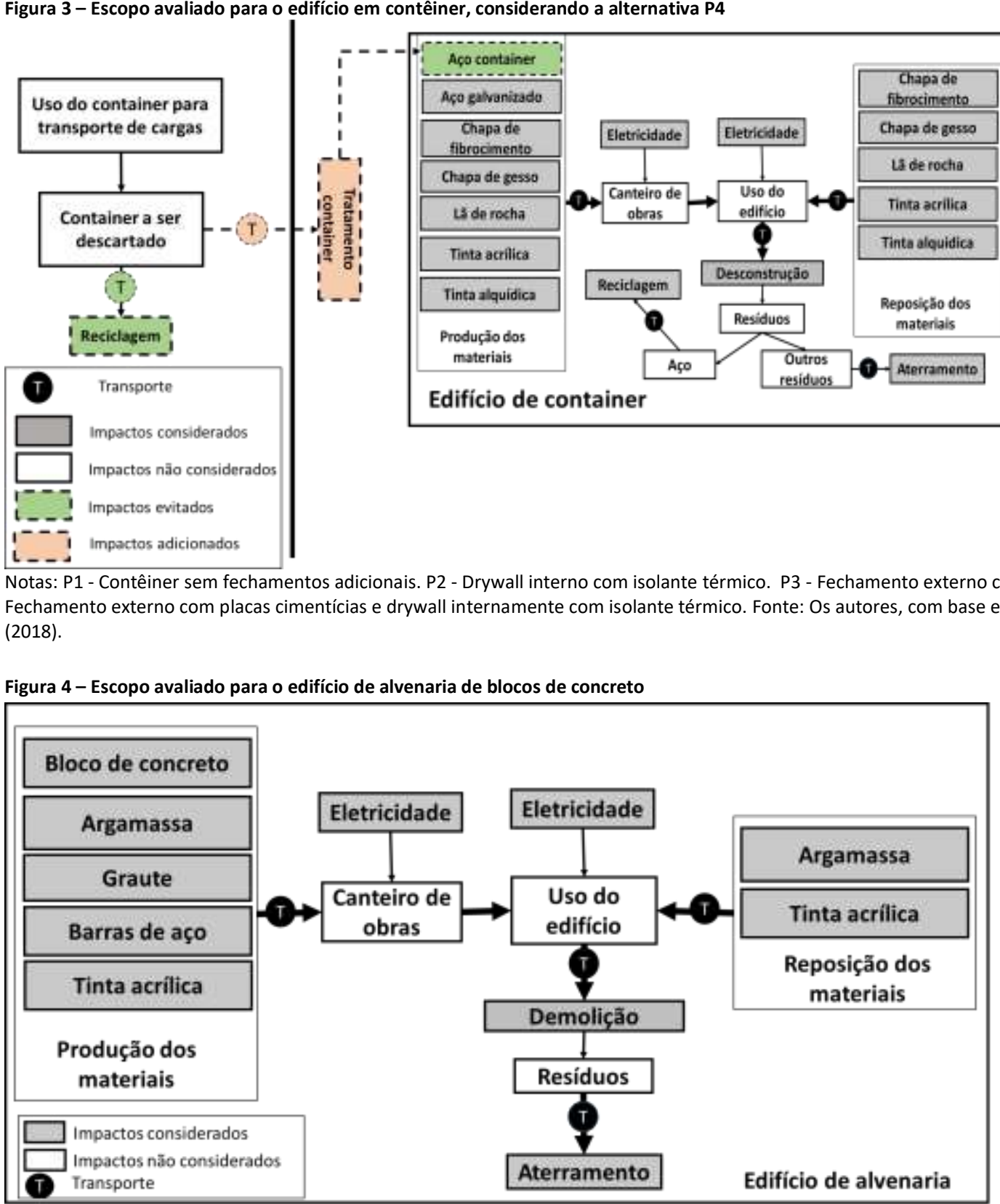

Fonte: Os autores.

Dessa forma, adotou-se o impacto do aço galvanizado primário ("novo") como evitado, considerando que $100 \%$ do aço do contêiner reaproveitado substituirá 100\% de chapas novas de aço galvanizado com um fator de correção de qualidade igual a 1. A procedência desse aço galvanizado, produzido na Ásia e importado para o Brasil, está disponível no banco de dados do Ecoinvent v.3.3 (PEREIRA et al., 2016). O critério de escolha desse material foi baseado no fato do mesmo possuir a unidade funcional em termos de desempenho térmico do contêiner e durabilidade (por exemplo, aço galvanizado $\mathrm{x}$ aço comum). $\mathrm{O}$ dataset foi "Steel electrogalvanised steel/Asia" que 
considera o uso de sucata para produção do aço, no entanto, os benefícios da reciclagem do aço no fim de vida não são contabilizados. Como o contêiner a ser reaproveitado precisa ser tratado para ser utilizado como edificação, foi considerado o consumo de energia gasto para seu tratamento $(0,11 \mathrm{kWh} / \mathrm{kg}$ de aço) (MAURIELLO, 2007 apud ISLAM et al., 2016).

Na distribuição de impactos, considerou-se que 100\% dos benefícios relacionados aos impactos evitados são quantificados nos impactos do ciclo de vida da edificação, ou seja, dando um destino ao contêiner que ficaria estocado ao final de sua vida útil para o transporte de cargas. No entanto, a NBR ISO 14040 (ABNT, 2009) determina a necessidade de Análise de Sensibilidade quando existe multifuncionalidade no sistema, com a utilização de mais de um método de distribuição de impactos.

Os impactos do transporte e o processo de reciclagem do aço do contêiner foram desconsiderados pois, de um lado, estas etapas entram como impactos evitados e, do outro, como impactos do fim de vida. Considerou-se que o transporte, para ambos os casos, é o mesmo. Nesse caso, eles se anulam. Logo, para os edifícios de contêiner foram considerados os impactos ambientais para o processo de reciclagem do aço galvanizado e aterramento em aterro de resíduos inertes de outros materiais, como lã de rocha, chapa de fibrocimento e chapa de gesso.

A limitação dessa escolha é que os impactos de reciclagem e transporte, para cada cenário (descarte do contêiner ou sua reutilização como edificação) ocorrerão em momentos diferentes. Ao longo dos 50 anos, as concentrações de diversos elementos na atmosfera podem mudar consideravelmente, assim como seus impactos ambientais. Para solucionar este problema, utilizou-se a modelagem dinâmica, chamada de ACV dinâmica. Alguns estudos, como o de Levasseur et al. (2010), apresentam um tipo de modelo dinâmico. No entanto, na pesquisa apresentada no presente artigo a ACV dinâmica não foi utilizada.

Para o sistema de alvenaria foi considerada a demolição e o encaminhamento dos resíduos gerados para um aterro de resíduos inertes. As mesmas distâncias de transporte entre os resíduos das alternativas de contêiner e de alvenaria foram consideradas.

\section{Inventário do Ciclo de Vida}

Para o inventário do ciclo de vida foram utilizados dados obtidos no banco de dados do Ecoinvent v.3.3 utilizando modelo do sistema do tipo "cut-off" com abordagem atribucional, dando preferência para dados brasileiros. Para dados não disponíveis foi realizada a troca da matriz de energia elétrica original pela a matriz brasileira, conforme Silva, Gomes e Saade (2018), além da adaptação das distâncias de transporte das atividades de mercado à montante. A discriminação dos dados utilizados será apresentada posteriormente.

Para o sistema de alvenaria, os processos de argamassa e graute foram modelados com base nas composições do Sistema Nacional de Pesquisa de Custos e Índices da Construção Civil (Sinapi) da Caixa Econômica Federal (2018), conforme Caldas, Lira e Sposto (2017) e Medeiros, Durante e Callejas (2018). Para os blocos de concreto foi utilizado o estudo de Souza et al. (2016) sobre alvenaria estrutural no Brasil.

Tendo em vista que o transporte dos materiais de construção tem uma grande variação devido às dimensões continentais do território brasileiro - localização do canteiro, das fábricas de produção e das lojas de materiais - foram adotadas diferentes distâncias de transporte terrestre no território brasileiro. Assumiu-se, então, uma distribuição triangular, conforme os valores da Tabela 3 (INVIDIATA; GHISI, 2016) sendo a variação 
tratada como desvio padrão dos resultados. Adotou-se, também, o modal rodoviário com modelo de motor EURO 3 com carga de 16-32 toneladas do banco de dados do Ecoinvent v. 3.3.

\begin{tabular}{cccc}
\hline Tabela 3 - Distâncias de transporte terrestre no Brasil consideradas \\
\hline Materiais & $\begin{array}{c}\text { Distância de transporte } \\
- \text { Min } \mathbf{( k m})\end{array}$ & $\begin{array}{c}\text { Distância de transporte } \\
-\mathbf{M e d}(\mathbf{k m})\end{array}$ & $\begin{array}{c}\text { Distância de transporte } \\
-\mathbf{M a ́ x}(\mathbf{k m})\end{array}$ \\
\hline Contêiner & 100 & 300 & 500 \\
\hline Aço galvanizado & 100 & 300 & 500 \\
\hline Chapa de gesso & 100 & 300 & 500 \\
\hline Chapa de fibrocimento & 100 & 300 & 500 \\
\hline Lã de rocha & 100 & 300 & 500 \\
\hline Tinta eletrostática & 100 & 400 & 1000 \\
\hline Tinta acrílica & 100 & 400 & 1000 \\
\hline Bloco de concreto & 100 & 300 & 500 \\
\hline Argamassa de cimento e & 50 & 100 & 300 \\
\hline cal & 50 & 100 & 300 \\
\hline Graute & 50 & 100 & 300 \\
\hline Barras de Aço & &
\end{tabular}

Fonte: Os autores com base em Invidiata e Ghisi (2016).

Para a reposição dos materiais utilizados nos fechamentos verticais adotaram-se períodos de vida útil definidos na NBR 15575-1 (ABNT, 2013), considerando um nível mínimo de desempenho. É importante salientar que norma utilizada como referência é de edifícios residenciais e não comerciais. No entanto, como não se tem nenhuma norma similar para a tipologia comercial, ela foi adotada. Para diferenciar os impactos ambientais em relação à absortância solar, foram considerados diferentes valores de reposição da tinta. Salienta-se que, para obter um valor de absortância de 0,3, é necessário que a cor se mantenha clara, sem o escurecimento ou manchas causadas por intempéries nas fachadas. Portanto, foi adotado um período de reposição da pintura com absortância de 0,3 de 3 em 3 anos, absortância de 0,6 de 5 em 5 anos e absortância de 0,9 de 10 em 10 anos. Esses valores estão dentro do intervalo definido na NBR 155751 (ABNT, 2013). Para as placas de gesso, placas de fibrocimento e blocos de concreto foi considerado pintura com tinta acrílica, enquanto que para os casos com contêiner sem fechamento foi adotada pintura com tinta eletrostática. No Quadro 1 são apresentados as atividades e os insumos, divididos por etapas do ciclo de vida da edificação, com seus respectivos datasets (do Ecoinvent) e fontes utilizadas na modelagem.

Avaliação do impacto do Ciclo de Vida

Na Avaliação do Impacto do Ciclo de Vida (AICV) foi utilizado o método IMPACT 2002+, v. 2.14, sendo avaliadas as seguintes categorias de danos: (1) Mudanças Climáticas, em $\mathrm{tCO}_{2 e}$ /edifício, (2) Saúde Humana, em DALY ${ }^{(2)}$ edifício; (3) Qualidade do Ecossistema, em $\mathrm{PDF}^{(3)} \cdot \mathrm{m}^{2}$.ano/edifício; (4) Depleção de Recursos, em MJ/edifício.

Nesse método, as categorias de impacto orientadas a problemas ("midpoint") potencial de aquecimento global, eutrofização, acidificação, depleção da camada de ozônio, etc. - são agrupadas em quatro categorias de danos que podem ser considerados do tipo "endpoint", conforme Humbert et al. (2012). Esse método foi escolhido por reduzir as categorias de impactos a serem avaliadas no estudo, facilitar a interpretação dos resultados e por se basear em outros estudos que avaliaram os impactos ambientais de edificações para o contexto brasileiro, como Souza et al. (2016) e Caldas, Lira e Sposto (2017). 
CALDAS, Lucas Rosse; ABREU-HARBICH, Loyde Vieira de; HORA, Karla Emmanuela Ribeiro.

Avaliação ambiental de alternativas construtivas de um edifício contêiner

\begin{tabular}{|c|c|}
\hline Insumos e atividades & Datasets e fontes \\
\hline \multicolumn{2}{|r|}{ Etapa de produção } \\
\hline \multicolumn{2}{|r|}{ Contêiner } \\
\hline Aço galvanizado & Steel electrogalvanised steel/Asia \\
\hline Chapa de gesso & Gypsum plasterboard $\{$ RoW $\}$ \\
\hline Chapa de fibrocimento & Fibre cement facing tile $\{$ RoW $\}$ \\
\hline Lã de rocha & Stone wool, packed $\{$ RoW $\}$ \\
\hline Tinta eletrostática & Electrostatic paint $\{$ GLO $\} \mid$ market for \\
\hline Tinta acrílica & Acrylic varnish, without water, in $87.5 \%$ solution state $\{\mathrm{GLO}\} \mid$ \\
\hline Eletricidade & Market for electricity, medium voltage $\{B R\}$ \\
\hline \multicolumn{2}{|r|}{ Alvenaria de bloco de concreto } \\
\hline Bloco de concreto & Souza et al. (2016) \\
\hline Argamassa mista de cimento e cal & $\begin{array}{c}\text { Cement CP-II (Autores), } \\
\text { Lime, hydrated, packed }\{\text { RoW\}, Sand }\{\text { RoW }\}\end{array}$ \\
\hline Graute & $\begin{array}{l}\text { Cement CP-II (Autores), } \\
\text { Lime, hydrated, packed }\{\text { RoW }\} \text {, Sand }\{\text { RoW }\} \text {, Gravel, round }\{\text { RoW }\}\end{array}$ \\
\hline Aço & Reinforcing steel $\{$ RoW $\}$ \\
\hline Tinta acrílica & Acrylic varnish, without water, in $87.5 \%$ solution state $\{$ RoW $\}$ \\
\hline Eletricidade & Market for electricity, medium voltage $\{B R\}$ \\
\hline \multicolumn{2}{|r|}{ Etapa de transporte } \\
\hline Transporte & Transport, freight, lorry 16-32 metric ton, EURO3 \{GLO\} \\
\hline \multicolumn{2}{|r|}{ Uso de energia } \\
\hline Eletricidade & Market for electricity, medium voltage $\{B R\}$ \\
\hline \multicolumn{2}{|r|}{ Etapa de fim de vida } \\
\hline Demolição & Diesel, burned in building machine $\{\mathrm{GLO}\}$ \\
\hline Transporte & Transport, freight, lorry 16-32 metric ton, EURO3 \{GLO\} \\
\hline Disposição final em aterro de resíduos inertes & $\begin{array}{c}\text { Waste concrete, not reinforced }\{\text { RoW }\} \mid \text { treatment of waste concrete, not } \\
\text { reinforced, collection for final disposal }\end{array}$ \\
\hline
\end{tabular}

Nota: RoW - Rest of World. GLO - Global. BR - Brazil. Fonte: Os autores

Análise de sensibilidade

Tendo em vista a questão da multifuncionalidade, realizou-se uma análise de sensibilidade considerando diferentes contribuições dos impactos evitados, utilizandose o método "50/50" e dois datasets de aço galvanizado do banco de dados do Ecoinvent. A distribuição de impactos foi realizada a partir da relação produtor (setor de transportes de cargas) / consumidor (setor da construção civil): o/100 (caso original) e 50/50. Nesse método, os benefícios e cargas ambientais devido à reciclagem ou ao reaproveitamento são compartilhados entre o uso anterior e posterior (SCHRIJVERS; LOUBET; SONNEMANN, 2016).

Os datasets utilizados foram: "Galvanized steel sheet, at plant/RNA" e "Steel hot dip galvanized", considerando a produção na China e o transporte para o Brasil. Portanto, no final, seis cenários de impactos evitados foram avaliados.

\section{Resultados e discussão}

As Figuras 5, 6, 7 e 8 apresentam os resultados para mudanças climáticas, saúde humana, qualidade dos ecossistemas e depleção de recursos, respectivamente.

A etapa de uso de energia da edificação foi a mais impactante do ciclo de vida para as quatro categorias de impacto avaliadas, seguindo resultados similares aos de Cabeza et al. (2014). O aumento da absortância promoveu o aumento do consumo de energia elétrica e dos demais impactos ambientais associados. 
CALDAS, Lucas Rosse; ABREU-HARBICH, Loyde Vieira de; HORA, Karla Emmanuela Ribeiro.

Avaliação ambiental de alternativas construtivas de um edifício contêiner

Figura 5 - Mudanças Climáticas, considerando o cenário com contribuição dos impactos evitados produtor/consumidor 0/100. (A) São Paulo. (B) rasília. (C) Rio de Janeiro. (D) Teresina

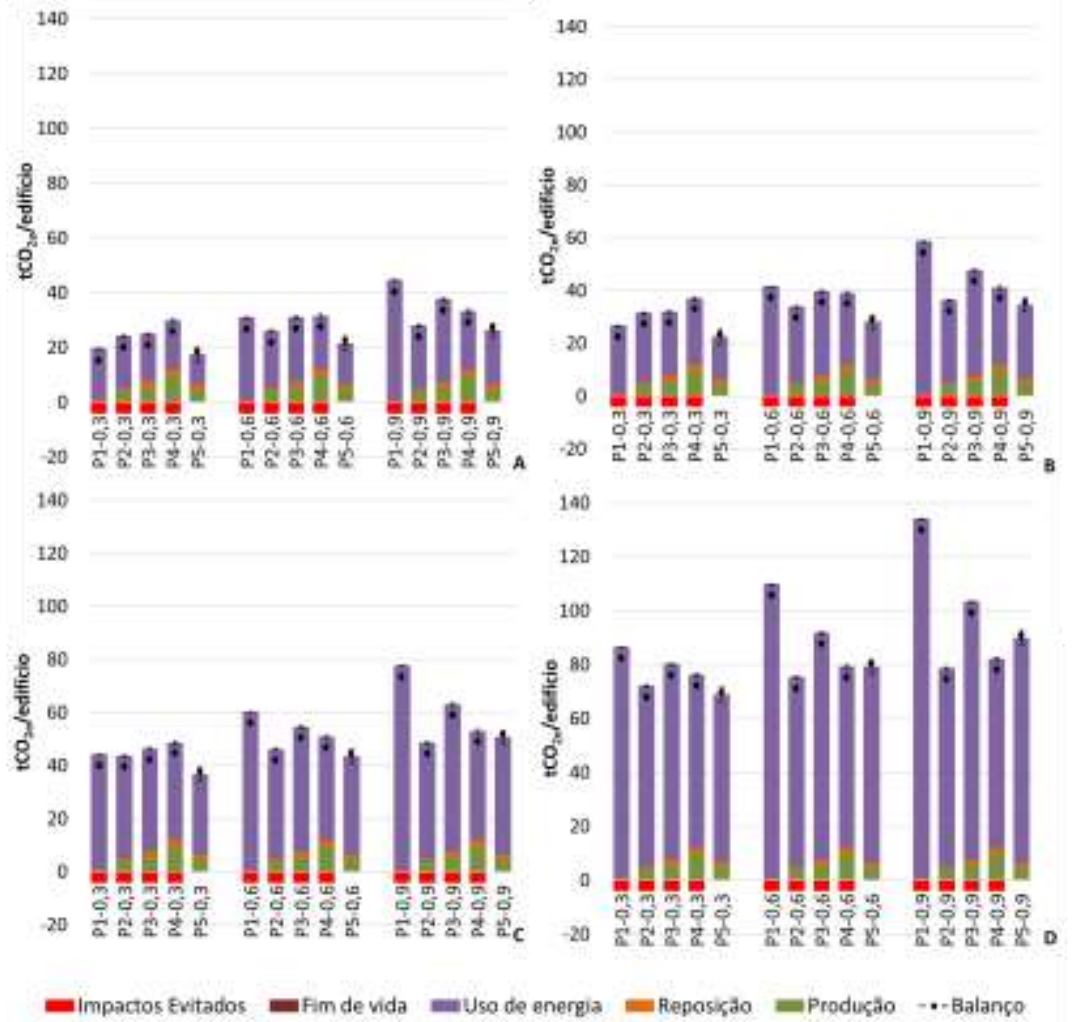

Nota: P1 - Contêiner sem fechamentos. P2 - Contêiner com drywall (internamente). P3 - Contêiner com placas cimentíficas (externamente). P4 Contêiner com drywall (internamente) e placas cimentícias (externamente). P5 - Alvenaria blocos de concreto. Absortâncias 0,3, 0,6 e 0,9. Fonte: Os autores

Figura 6 - Saúde Humana, considerando o cenário com contribuição dos impactos evitados produtor/consumidor 0/100. (A) São Paulo. (B) Brasília. (C) Rio de Janeiro. (D) Teresina

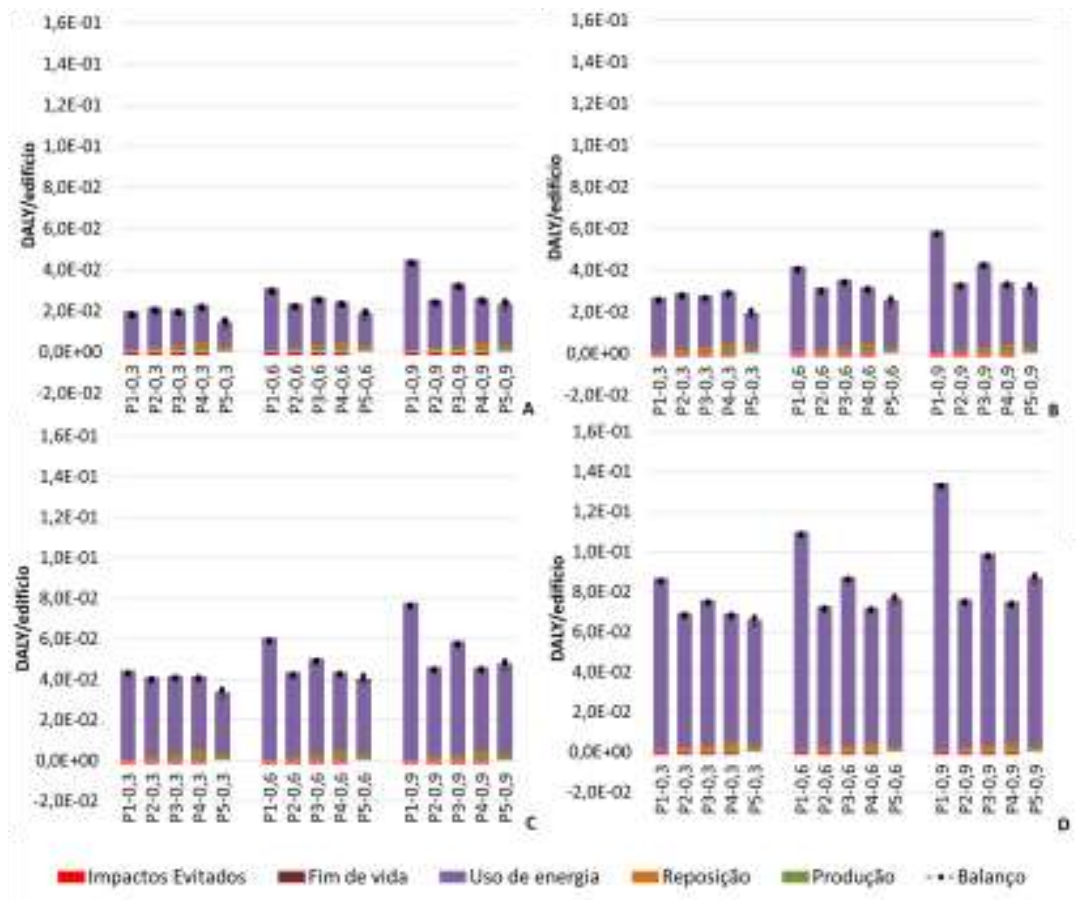

Nota:P1 - Contêiner sem fechamentos. P2 - Contêiner com drywall (internamente). P3 - Contêiner com placas cimentíficas (externamente). P4 Contêiner com drywall (internamente) e placas cimentícias (externamente). P5 - Alvenaria blocos de concreto. Absortâncias 0,3, 0,6 e 0,9. Fonte: Os autores 
CALDAS, Lucas Rosse; ABREU-HARBICH, Loyde Vieira de; HORA, Karla Emmanuela Ribeiro.

Avaliação ambiental de alternativas construtivas de um edifício contêiner

Figura 7 - Qualidade do Ecossistema, considerando o cenário com contribuição dos impactos evitados produtor/consumidor 0/100. (A) São Paulo. (B) Brasília. (C) Rio de Janeiro. (D) Teresina

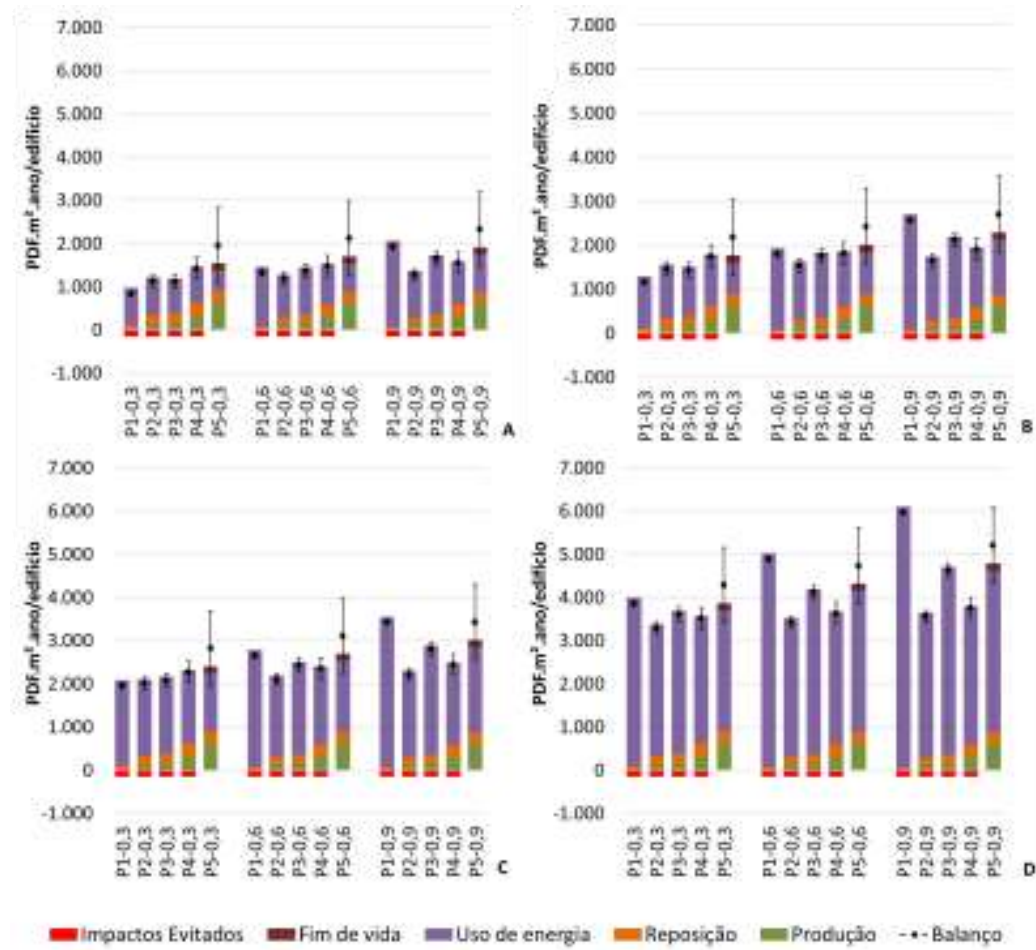

Nota: P1 - Contêiner sem fechamentos. P2 - Contêiner com drywall (internamente). P3 - Contêiner com placas cimentíficas (externamente). P4 Contêiner com drywall (internamente) e placas cimentícias (externamente). P5 - Alvenaria blocos de concreto. Absortâncias 0,3, 0,6 e 0,9. Fonte: Os autores

Figura 8 - Depleção de Recursos, considerando o cenário com contribuição dos impactos evitados produtor/consumidor 0/100. (A) São Paulo. (B) Brasília. (C) Rio de Janeiro. (D) Teresina

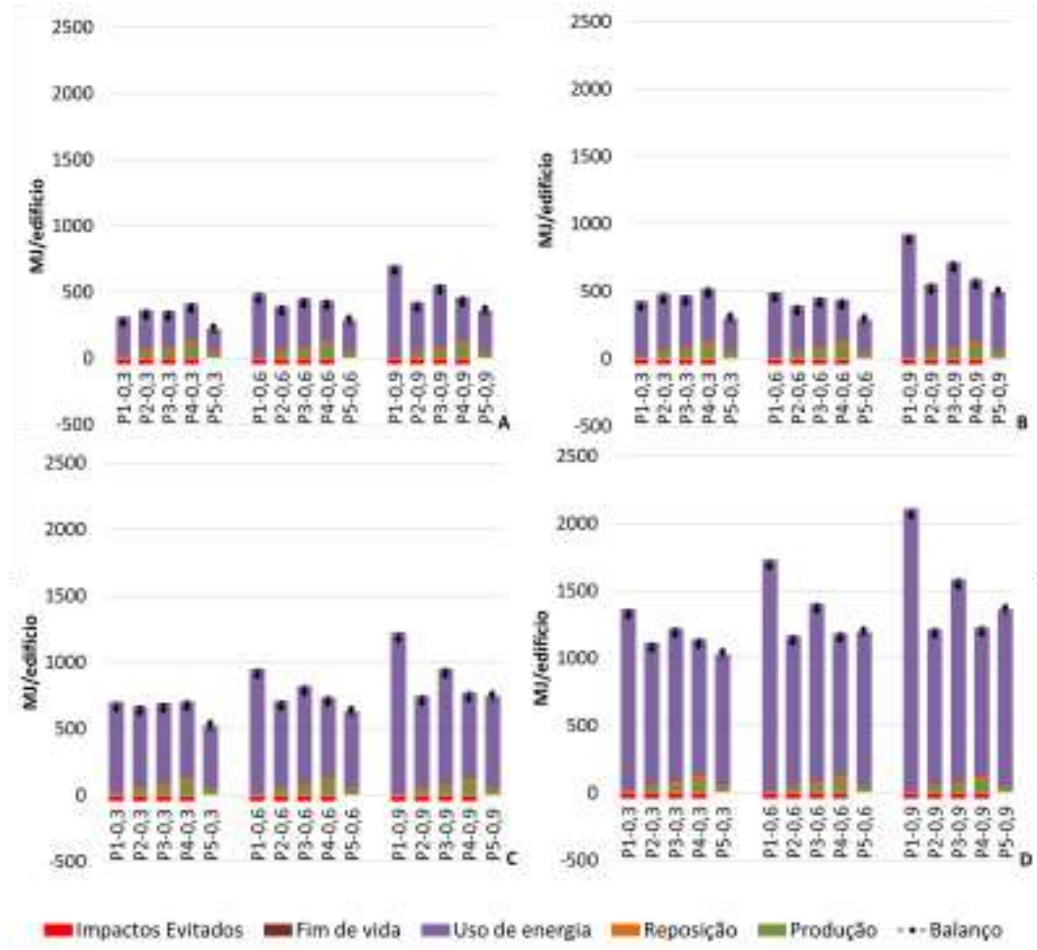

Nota: P1 - Contêiner sem fechamentos. P2 - Contêiner com drywall (internamente). P3 - Contêiner com placas cimentíficas (externamente). P4 Contêiner com drywall (internamente) e placas cimentícias (externamente). P5 - Alvenaria blocos de concreto. Absortâncias 0,3, 0,6 e 0,9. Fonte: Os autores 
$\mathrm{O}$ aço do contêiner utilizado nas alternativas $\mathrm{P} 1$ e $\mathrm{P} 3$ está sem nenhuma proteção e este material é de elevada condutividade térmica, resultando em uma alta transmitância térmica. Esses resultados mostram que, para essas alternativas construtivas, a absortância é um item fundamental de projeto, principalmente para as cidades de Teresina e Rio de Janeiro. Esses resultados também foram observados por Viana, Souza e Gomes (2019).

A P2, com o uso de drywall no interior e isolante térmico, foi a mais vantajosa para todas as cidades avaliadas. Esse resultado corrobora com o resultado obtido por Viana Souza e Gomes (2019), em que o isolamento térmico nos fechamentos externos de uma edificação de contêiner se mostrou indispensável nas zonas bioclimáticas 2 , 3 e 8 . A alternativa $\mathrm{P}_{4}$ foi a que apresentou menor consumo de energia, mas é a que tem maior consumo de materiais. A alternativa $\mathrm{P}_{5}$ - alvenaria de blocos de concreto - se mostrou mais vantajosa que os cenários de contêiner devido ao menor uso de energia durante a operação da edificação.

De acordo com o inventário utilizado, os impactos ambientais do tratamento do contêiner foram insignificantes pois há um baixo consumo de energia requerido no tratamento e a uma elevada participação de fontes renováveis (superior a 70\%) na matriz de energia elétrica do Brasil. A etapa de fim de vida também foi insignificante, corroborando com outros estudos da literatura, como apontam Cabeza et al. (2014).

Verificou-se que os impactos ambientais de produção, reposição e fim de vida foram menores para os cenários com contêiner. No entanto, o uso de energia foi a etapa mais impactante para a maioria das categorias de dano, fato também verificado por Islam et al. (2016).

Assim, é necessário reduzir os impactos totais dessa etapa no ciclo de vida. Para tal, recomenda-se a produção de energias renováveis, como o uso de painéis fotovoltaicos (PV) em edifícios de contêiner para uso comercial, conforme recomendado por Garrido (2015). Salienta-se que há uma tendência dos países, inclusive do Brasil, de descarbonizar a matriz de energia elétrica com o aumento de participação de fontes renováveis e limpas (UN, 2017).

Enquanto uma matriz de baixo carbono não se concretiza, a utilização de PV pode ser uma solução viável, visto que foi a fonte energética renovável que mais cresceu nos últimos, anos no Brasil, segundo Luna et al. (2019). Garrido (2015) recomenda o emprego de PV para edificações contêineres. No entanto, é necessário um novo estudo para confirmar essa recomendação, inclusive avaliando quais zonas bioclimáticas possuem maior uso potencial e quais impactos ambientais estão envolvidos no ciclo de vida dos PV.

Comparando a localização das quatro cidades de zonas bioclimáticas diferentes percebe-se que as edificações das zonas 7 e 8 foram as que consumiram mais energia e, consequentemente, causaram maiores danos ambientais. Em tais localidades o edifício de contêiner com os sistemas $\mathrm{P}_{2}$ (drywall) e P4 (placas cimentícias e drywall) foram mais vantajosos que o $\mathrm{P}_{5}$ (alvenaria), principalmente para a categoria de Saúde Humana e Qualidade do Ecossistema e para as absortâncias 0,6 e 0,9. Estes resultados podem ser explicados pela influência da radiação solar em superfícies que absorvem mais a energia solar (cores mais escuras) em regiões de clima quente. Assim, a necessidade de um isolante térmico para diminuir a transmissão do calor foi maior, sendo o caso das alternativas $\mathrm{P} 2$ e $\mathrm{P} 4$.

A etapa de transporte dos materiais e componentes (com as distâncias representadas pelas barras de erros nas figuras) só se mostrou significativa para a categoria de 
Qualidade do Ecossistema, onde obteve uma participação média de $43 \%$ para a alternativa de alvenaria de concreto, enquanto que para as outras categorias foram inferiores a $10 \%$. No caso da alvenaria de concreto o resultado se deve à maior massa da edificação.

A zona bioclimática teve influência direta nos resultados das quatro categorias de danos ambientais avaliadas durante o ciclo de vida das edificações. Dependendo das condições climáticas, houve uma variação no consumo de energia elétrica para o resfriamento do ambiente e, consequentemente, uma variação nos impactos ambientais para a produção de energia. A cidade de Teresina, por exemplo, localizada na zona bioclimática 7, foi a que apresentou maiores impactos ambientais. Estes resultados mostram a importância de considerar as diferentes zonas bioclimáticas nos estudos de ACV.

Na Figura 9 são apresentados os perfis ambientais para as etapas de produção dos materiais utilizados nas alternativas avaliadas.

Figura 9 - Perfil ambiental para produção das alternativas construtivas, considerando o cenário com contribuição dos impactos evitados produtor/consumidor 0/100. (A) Mudanças Climáticas. (B) Saúde Humana. (C) Qualidade do Ecossistema. (D) Depleção de recursos
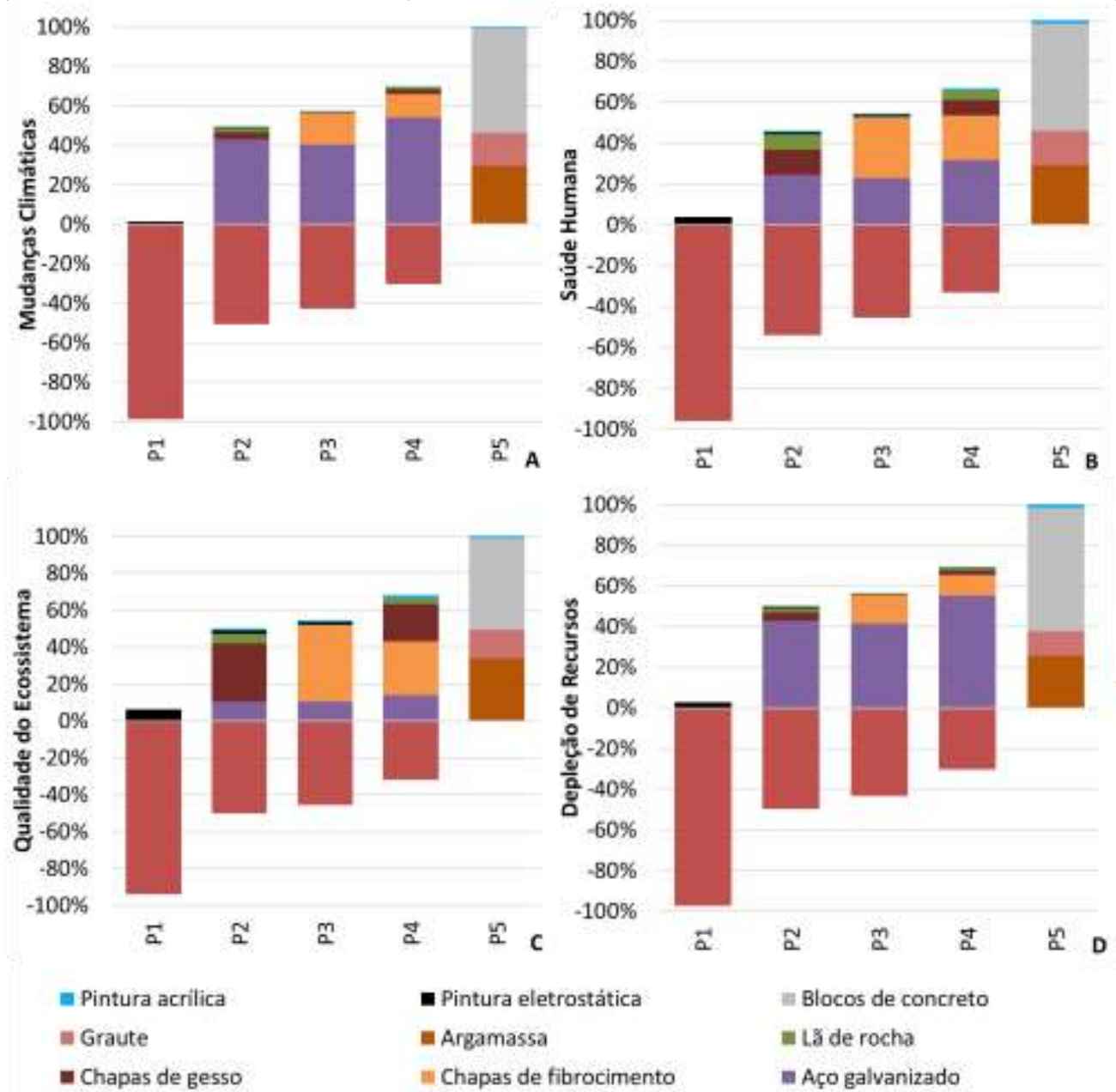

E Pintura acrilica

m Graute

- Chapas de gesso

- Aço galvanizado container
- Pintura eletrostática

argamassa

in Chapas de fibrocimento

P1 - Contêiner sem fechamentos. P2 - Contêiner com drywall (internamente). P3 - Contêiner com placas cimentíficas (externamente). P4 - Contêiner Nota: com drywall (internamente) e placas cimentícias (externamente). P5 - Alvenaria blocos de concreto. Fonte: Os autores.

Para a categoria de Mudanças Climáticas, a produção do aço galvanizado e drywall utilizados nas vedações tiveram grande participação nos resultados devido ao processo de galvanização, que consome muita energia, corroborando com os resultados de Bueno et al. (2016). A chapa de fibrocimento também apresentou uma contribuição 
importante nas alternativas $\mathrm{P}_{3}$ e $\mathrm{P}_{4}$, enquanto que as chapas de gesso tiveram uma contribuição mínima. O sistema de alvenaria foi o item de maior contribuição, devido à produção de blocos de concreto, seguido da argamassa de revestimento, devido à produção do cimento Portland utilizado na confecção desses produtos.

Para a categoria de Saúde Humana, o cenário com contêineres com isolante térmico foi mais vantajoso que o de alvenaria, principalmente para as cidades de Teresina e Rio de Janeiro. A etapa de uso do edifício também se mostrou a mais impactante, seguida da produção, reposição e fim de vida. $O$ transporte teve uma pequena influência para os cenários de contêiner e maior para o cenário de alvenaria. Quando foram contabilizados os impactos evitados da produção do aço utilizado no contêiner houve um ganho para esse sistema, tendo em vista que a produção de uma nova parede de aço teria grande participação.

Das quatro categorias de dano avaliadas, a Qualidade do Ecossistema nos sistemas com contêineres foi mais vantajosa em relação ao cenário de alvenaria. Isso se deve a quatro fatores principais: (1) o aço galvanizado utilizado nos elementos de fechamento possuem baixos impactos para essa categoria; (2) a produção de blocos de concreto possui grandes impactos; (3) essa categoria é a que recebe menor influência da etapa do consumo de energia no uso da edificação; (4) o transporte dos materiais teve uma grande contribuição, o que fez o cenário de alvenaria tivesse um impacto superior aos cenários de contêiner já que sua massa é mais elevada (com uma diferença de aproximadamente 350\%).

Para a categoria de Depleção de Recursos, os impactos e a contribuição dos materiais se assemelham aos resultados de Mudanças Climáticas, com o aço galvanizado e blocos de concreto sendo os mais impactantes para as alternativas de contêiner e alvenaria, respectivamente. Essa categoria representa o consumo de recursos, sendo que o uso de combustíveis fósseis na produção desses materiais (no caso dos blocos de concreto para a produção do cimento Portland) têm grande influência nos resultados. Maior queima de combustíveis fósseis leva, também, a um aumento de Gases de Efeito Estufa (GEE), fazendo que esses materiais também tenham um maior impacto de Mudanças Climáticas.

Na Figura 10 são apresentados os perfis ambientais para as etapas de reposição dos materiais utilizados.

Para as alternativas P1 e P2 (sem uso de chapas de fibrocimento), a pintura eletrostática e a reposição das chapas de gesso foram os materiais mais impactantes, respectivamente. Para a categoria de Saúde Humana as chapas de fibrocimento foram as mais significativas, seguidas pelas tintas nos casos de $\mathrm{P}_{3}$ e $\mathrm{P}_{4}$. No cenário $\mathrm{P}_{5}$ a argamassa de revestimento foi o material mais impactante para as quatro categorias de impacto avaliadas. Os resultados apresentados na Figura 11 são referentes ao cenário de reposição de cinco em cinco anos da pintura acrílica. No entanto, para o cenário com menor período de reposição, de três em três anos, a pintura aumentou sua participação e se tornou o insumo mais impactante para a alternativa P5. Como neste estudo foi considerada toda a reposição do material (que seria o pior caso), podem ser realizadas manutenções (de preferência preventiva) e reparos pontuais, prolongando a vida útil dos materiais e consequentemente diminuindo os impactos ambientais dessa etapa.

Nas Figuras 11 e 12 são apresentados os resultados da Análise de Sensibilidade para os Impactos Evitados, para a absortância de 0,6 (caso intermediário) e para as cidades de São Paulo e Teresina, onde ocorreram os menores e maiores impactos ambientais, respectivamente. Na Figura 13 são apresentados os resultados da Análise de Sensibilidade quando a etapa de uso da edificação não é considerada. 
Figura 10 - Perfil ambiental para reposição dos materiais utilizados nas alternativas construtivas, considerando o cenário com contribuição dos impactos evitados produtor/consumidor 0/100 (cenário com absortância 0,6). (A) Mudanças Climáticas. (B) Saúde Humana. (C) Qualidade do Ecossistema. (D) Depleção de recursos

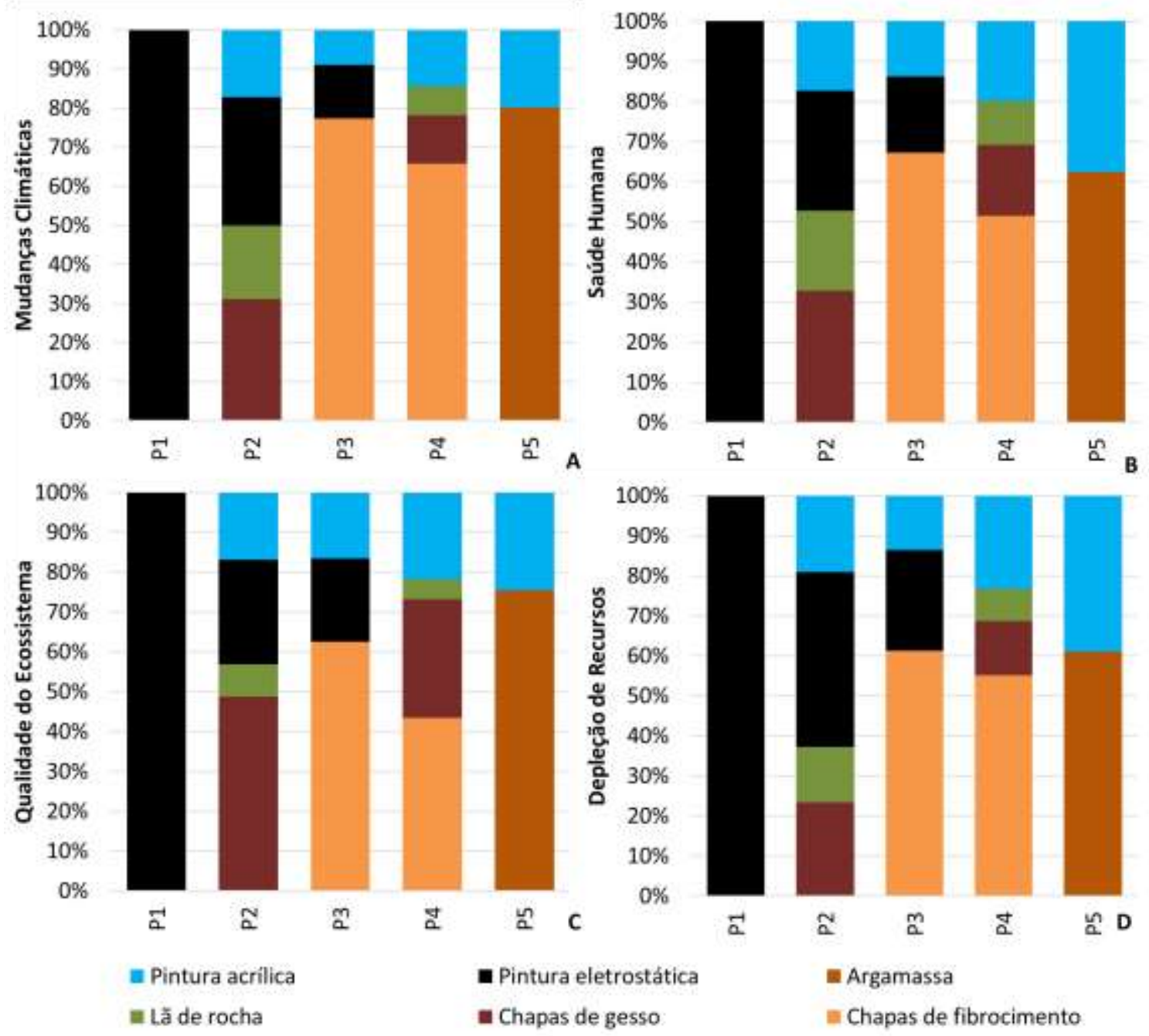

Nota: P1 - Contêiner sem fechamentos. P2 - Contêiner com drywall (internamente). P3 - Contêiner com placas cimentíficas (externamente). P4 Contêiner com drywall (internamente) e placas cimentícias (externamente). P5 - Alvenaria blocos de concreto. Fonte: Os autores.

Do ponto de vista metodológico da aplicação da ACV é importante contabilizar os benefícios ambientais em termos de impactos evitados quando resíduos são utilizados para a produção de novos materiais ou sistemas construtivos, conforme afirmam Silva, Gomes e Saade (2018). Para a categoria de dano de Mudanças Climáticas, em específico do impacto evitado para a produção de aço galvanizado, essa consideração teve uma influência considerável nos resultados finais (superior a 10\% para a cidade de São Paulo).

Para o caso da cidade de São Paulo, a Análise de Sensibilidade dos impactos evitados mostrou ter uma maior influência (média de 10\%) devido à etapa de uso da edificação ser menor; ocorrendo o contrário (menor que 5\%) para a cidade de Teresina. Quando a etapa de uso não foi considerada, a diferença dos impactos evitados teve uma grande influência nos resultados (superior a 200\%), assim como o aço galvanizado teve um grande impacto na categoria de Mudanças Climáticas. A alternativa P1, em que a massa do contêiner representa a maior parcela da edificação, apresentou impactos negativos ou positivos, dependendo das escolhas para a quantificação dos impactos evitados. 
CALDAS, Lucas Rosse; ABREU-HARBICH, Loyde Vieira de; HORA, Karla Emmanuela Ribeiro.

Avaliação ambiental de alternativas construtivas de um edifício contêiner

Figura 11 - Análise de Sensibilidade dos Impactos Evitados para a cidade de São Paulo. (A) Mudanças Climáticas. (B) Saúde Humana. (C) Qualidade do Ecossistema. (D) Depleção de recursos. Resultados normalizados pelo cenário de base (com contribuição 0/100 e inventário 1)

$140 \%$

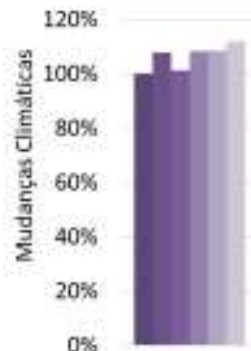

$\vec{a}$

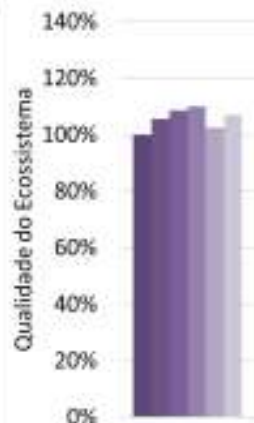

s

- 0/100-Inventảrio 1

=50/50-Inventário 2

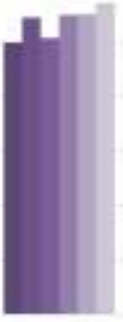

ล

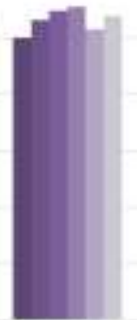

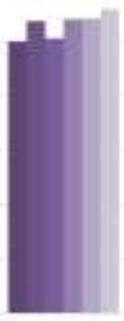

m

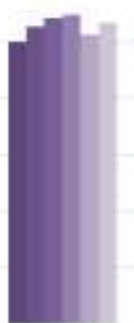

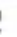

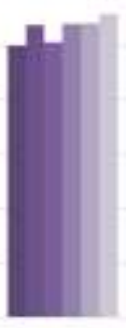

목 $140 \%$

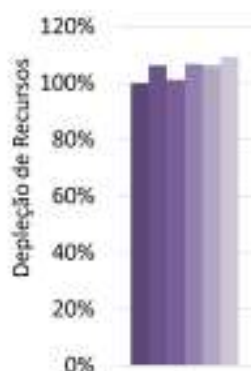

a

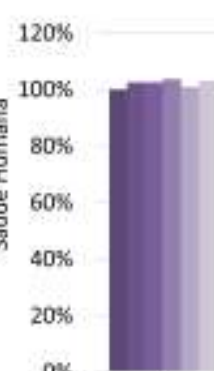

s

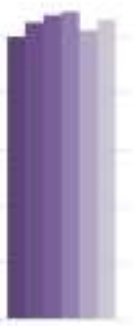

c

- 50/50 - Inventário 1

s $0 / 100$ - Inventário3

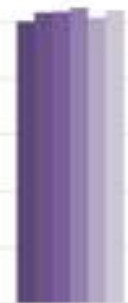

ฉ

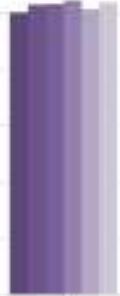

m

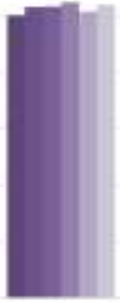

ฉ. $\mathrm{B}$

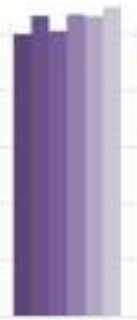

$\mathbb{E}$

- 0/100-Inventário 2

a 50/50 - Inventário 3

Nota: P1 - Contêiner sem fechamentos. P2 - Contêiner com drywall (internamente). P3 - Contêiner com placas cimentíficas (externamente). P4 Contêiner com drywall (internamente) e placas cimentícias (externamente). Inventário 1: Steel electrogalvanised steel/Asia Inventário 2: Galvanized steel sheet, at plant/RNA. Inventário 3: Steel hot dip galvanized. Fonte: Os autores.

Figura 12 - Análise de Sensibilidade dos Impactos Evitados para a cidade de Teresina. (A) Mudanças Climáticas. (B) Saúde Humana. (C) Qualidade do Ecossistema. (D) Depleção de recursos. Resultados normalizados pelo cenário de base (com contribuição 0/100 e inventário 1 )

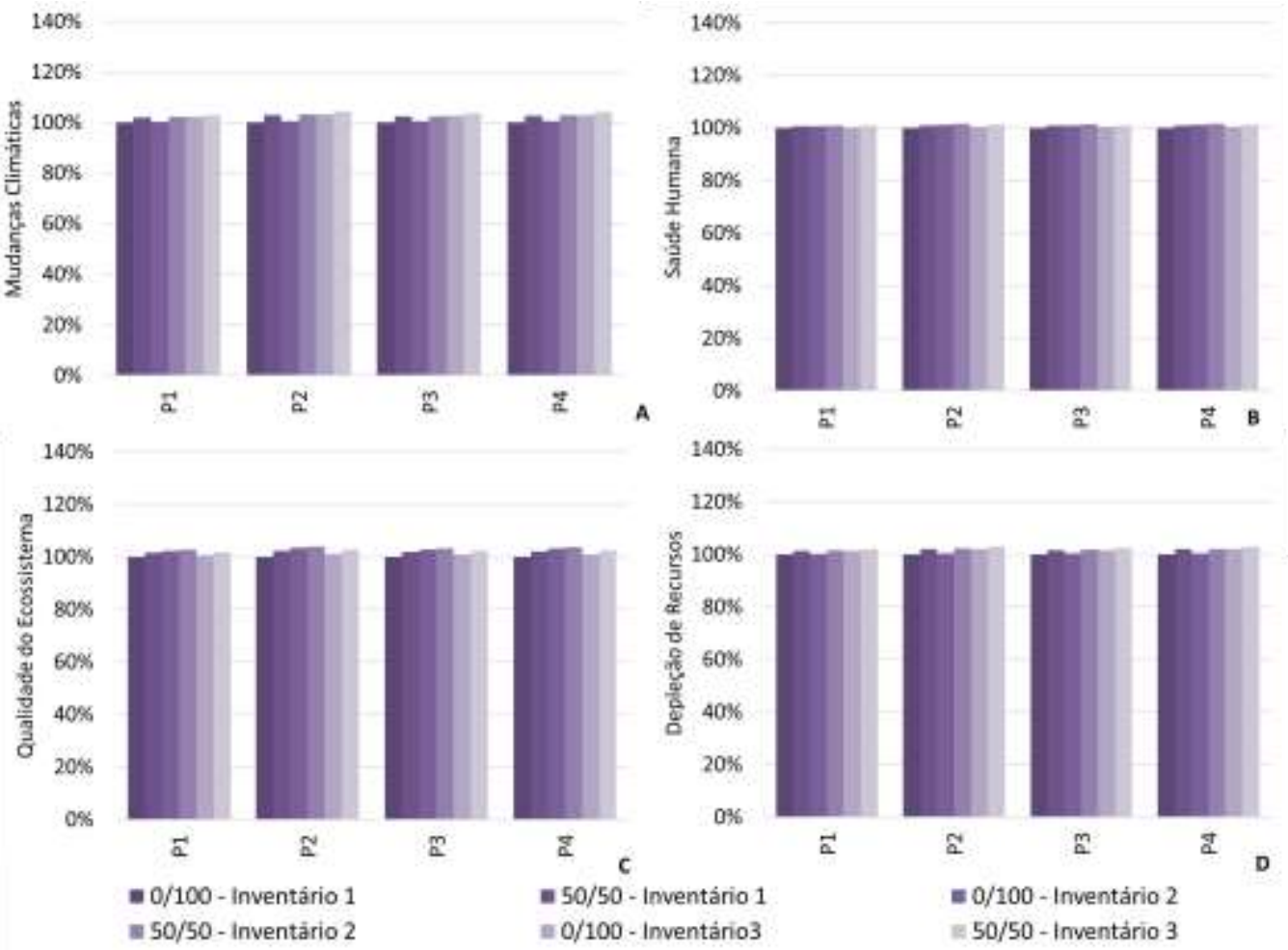

Nota: P1 - Contêiner sem fechamentos. P2 - Contêiner com drywall (internamente). P3 - Contêiner com placas cimentíficas (externamente). P4 Contêiner com drywall (internamente) e placas cimentícias (externamente). Inventário 1: Steel electrogalvanised steel/Asia Inventário 2: Galvanized steel sheet, at plant/RNA. Inventário 3: Steel hot dip galvanized. Fonte: Os autores. 


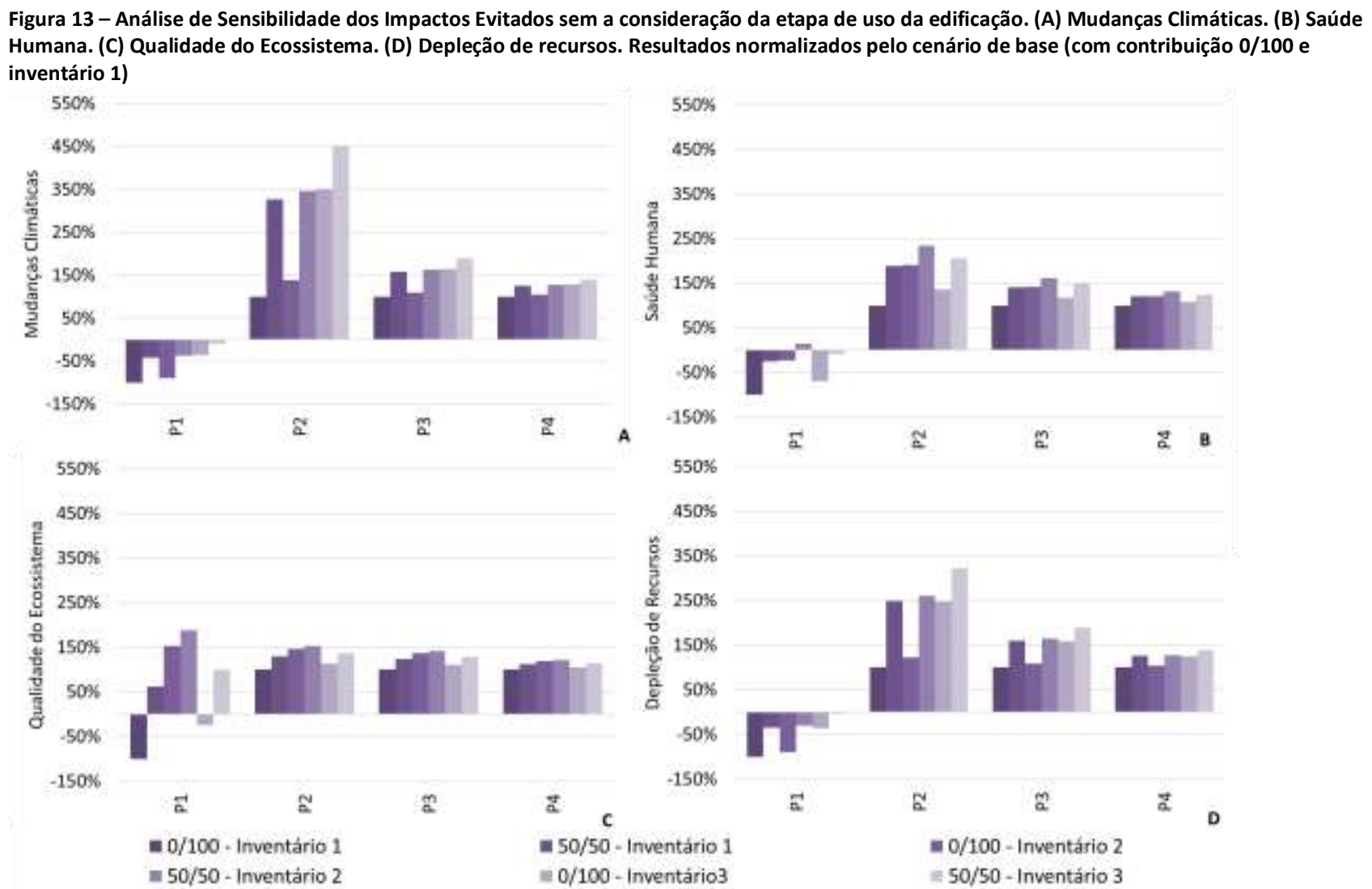

Nota: P1 - Contêiner sem fechamentos. P2 - Contêiner com drywall (internamente). P3 - Contêiner com placas cimentíficas (externamente). P4 Contêiner com drywall (internamente) e placas cimentícias (externamente). P5 - Alvenaria blocos de concreto. Inventário 1: Steel electrogalvanised steel/Asia Inventário 2: Galvanized steel sheet, at plant/RNA. Inventário 3: Steel hot dip galvanized. Fonte: Os autores.

É importante lembrar que os benefícios dos impactos evitados foram quantificados de acordo com o método utilizado e as premissas adotadas e não devido a um efeito físico, como por exemplo sequestro de $\mathrm{CO}_{2}$ que ocorre pelos biomateriais, como a madeira. Neste sentido, a escolha dos métodos de distribuição dos impactos evitados entre produtor e consumidor, o inventário utilizado e as etapas do ciclo de vida da edificação devem estar claros e bem justificados e são uma análise importante para esse tipo de sistema, como mostrou a Análise de Sensibilidade.

\section{Diretrizes ambientais de projeto para edifícios de contêiner para uso comercial}

O Quadro 2 apresenta diretrizes de projeto para melhoria do desempenho ambiental de edifícios de contêineres para fins comerciais, segundo as categorias de danos ambientais avaliadas.

Os "X" e diferentes cores representam o nível de importância das diretrizes para cada categoria de dano ambiental avaliada, sendo "X" e cor verde para um nível baixo, "XX" e cor amarelo, médio e "XXX" e cor vermelho, alto. Os pesos foram definidos segundo o critério: " $x$ " - participação (exemplo: participação do aço galvanizado nos impactos de produção) ou diferença (exemplo: diferença entre os resultados com absortância de $0,3,0,6$ e 0,9$) \leq 10 \%$ nos impactos ambientais; "XX" - participação ou diferença $>10 \%$ e $\leq$ 30\%; "XXX" - participação ou diferença > 30\%. 
CALDAS, Lucas Rosse; ABREU-HARBICH, Loyde Vieira de; HORA, Karla Emmanuela Ribeiro.

Avaliação ambiental de alternativas construtivas de um edifício contêiner

\begin{tabular}{|c|c|c|c|c|}
\hline \multirow[b]{2}{*}{ Diretrizes } & \multicolumn{4}{|c|}{ Danos Ambientais } \\
\hline & $\begin{array}{l}\text { Mudanças } \\
\text { climáticas }\end{array}$ & Saúde Humana & $\begin{array}{l}\text { Qualidade do } \\
\text { ecossistema }\end{array}$ & $\begin{array}{l}\text { Depleção de } \\
\text { recursos }\end{array}$ \\
\hline a. Reutilizar contêineres & $x x x$ & $\mathrm{xxx}$ & $\mathrm{xxx}$ & $\mathrm{xxx}$ \\
\hline b. Projeto adequado à zona bioclimática & $x x x$ & $x x x$ & $x x x$ & $x x x$ \\
\hline $\begin{array}{l}\text { c. Utilização de cores claras na envoltória, } \\
\text { absortância }(\alpha) \text { igual a } 0,3\end{array}$ & $\mathrm{xxx}$ & $x x x$ & $\mathrm{xxx}$ & $x x x$ \\
\hline d. Uso de isolante térmico & $x x x$ & $x x x$ & $x x x$ & $x x x$ \\
\hline $\begin{array}{l}\text { e. Incentivo para projetos com o uso de PV para } \\
\text { produção de energia no local }\end{array}$ & $x \mathrm{xx}$ & $\mathrm{xxx}$ & $\mathrm{xxx}$ & $x \mathrm{xx}$ \\
\hline f. Atenção para a produção dos materiais & $x x x$ & $x$ & $x x x$ & $x x x$ \\
\hline g. Substituição dos perfis de aço galvanizado & $\mathrm{xxx}$ & $\mathrm{xx}$ & $x$ & $\mathrm{xxx}$ \\
\hline h. Aquisição de contêineres próximo ao local de uso & $x$ & $x$ & $x x x$ & $\mathrm{x}$ \\
\hline i. Atenção para reposição da chapa de gesso & $x x$ & $x x$ & $x x x$ & $x \mathrm{x}$ \\
\hline j. Atenção para reposição da chapa de fibrocimento & $x x x$ & $\mathrm{xxx}$ & $\mathrm{xxx}$ & $x x x$ \\
\hline k. Atenção para reposição do isolante térmico & $\mathrm{xx}$ & $x x$ & $x$ & $x x$ \\
\hline I. Atenção para reposição da pintura & $x x$ & $\mathrm{xx}$ & $x x$ & $\mathrm{xx}$ \\
\hline m. Atenção para etapa de fim de vida & $x$ & $x$ & $x$ & $x$ \\
\hline
\end{tabular}

Fonte: Os autores.

As diretrizes b, c, d, e e são as mais importantes, visto que a tipologia comercial normalmente é climatizada artificialmente e a absortância dos materiais utilizados na envoltória influencia no aumento do consumo energético, principalmente em regiões de clima quente. Os impactos da reposição da pintura tiveram grande influência na quantidade de vezes em que a manutenção deveria ser realizada, o que também é resultante da cor (por exemplo: cores mais claras tendem a ser repintadas com mais frequência). Os perfis de aço galvanizado mostraram ser impactantes. Dessa forma, sugere-se a avaliação de outras alternativas, como por exemplo perfis de madeira (similares aos utilizados em sistemas de wood framing). Embora a diretriz "e" não tenha sido avaliada quantitativamente no presente estudo, ela foi considerada crítica pelo fato da etapa de uso ser a mais impactante do ciclo de vida.

\section{Conclusões}

Esta pesquisa comparou o desempenho ambiental no ciclo de vida de um edifício contêiner de uso comercial com diferentes estratégias construtivas de envoltória. Os cenários avaliados tiveram melhor ou pior desempenho em relação ao cenário comparativo de alvenaria de blocos de concreto, dependendo de: (1) configuração construtiva adotada, (2) zona bioclimática onde a edificação está inserida e (3) impacto ambiental avaliado, devendo assim, ser avaliados caso a caso.

Dentre as diferentes opções de fechamentos verticais para contêiner avaliadas neste estudo, aquela com sistema de drywall e isolante térmico interno foi a mais vantajosa nas categorias de impacto ambiental para todas as zonas bioclimáticas. A mudança nos valores de absortância solar das fachadas se mostrou um item crítico, sendo uma premissa importante durante a especificação de projeto desse sistema construtivo. A cidade de Teresina, localizada na zona bioclimática 7, foi a que apresentou maior consumo energético para climatização e maiores impactos ambientais durante o ciclo de vida para todas as alternativas de envoltória, dentre as zonas bioclimáticas analisadas nesta pesquisa.

O trabalho teve como principais limitações: o uso do banco de dados de ciclo de vida internacional, mesmo que de forma adaptada; o fato de terem sido avaliados somente os fechamentos verticais utilizados na envoltória e não serem consideradas questões como o entorno da edificação e o sombreamento por vegetação, por exemplo. 
A agregação de análises de relação custo-benefício, a utilização de materiais alternativos, por exemplo em substituição ao aço galvanizado e a produção de energia no local por painéis fotovoltaicos seriam tópicos de pesquisa a serem considerados futuramente.

\section{Notas}

(1) Aqueles que atendem as normas da International Organization for Standardization - ISO, conforme definição da ABNT NBR ISO 668: 2000 (CARBONARI; BARTH, 2015).

(2) DALY - DisabilityAdjusted Life Years (HUMBERT et al., 2012).

(3) PDF - Potentially Disappeared Fraction of species (HUMBERT et al., 2012).

\section{Referências}

ABNT - ASSOCIAÇÃO BRASILEIRA DE NORMAS TÉCNICAS. NBR 15220-2: Desempenho Térmico de Edificações. Parte 2: Métodos de cálculo da transmitância térmica, da capacidade térmica, do atraso térmico e do fator solar de elementos e componentes de edificações. Rio de Janeiro, 2005.

ABNT - ASSOCIAÇÃO BRASILEIRA DE NORMAS TÉCNICAS. NBR 15575-1: edificações habitacionais: desempenho: parte 1: requisitos gerais. Rio de janeiro, 2013.

ABNT - ASSOCIAÇÃO BRASILEIRA DE NORMAS TÉCNICAS. NBR ISO 14040: avaliação do ciclo de vida: princípios e estrutura. Rio de Janeiro, 2009a.

ATMACA, A.; ATMACA, N. Comparative life cycle energy and cost analysis of post-disaster temporary housings. Applied Energy, v. 171, 429-443, 2016. DOI: https://doi.org/10.1016/j.apenergy.2016.03.058

BUENO, C. et al. Sensitivity analysis of the use of Life Cycle Impact Assessment methods: a case study on building materials. Journal of Cleaner Production, v.112, n.20, p.2208-2220, jan. 2016. DOI:

https://doi.org/10.1016/j.jclepro.2015.10.006

CABEZA, L. F. et al. Life cycle assessment (LCA) and life cycle energy analysis (LCEA) of buildings and the building sector: A review. Renewable and Sustainable Energy Reviews, v.29, n.1, p. 394-416, jan. 2014. DOI: https://doi.org/10.1016/j.rser.2013.08.037

CAIXA ECONÔMICA FEDERAL. Sistema Nacional de Pesquisa de Custos e Índices da Construção Civil. Tabela de Custos de Composições Analítica. 2018. Disponível em: <http://www.caixa.gov.br/poder-publico/apoio-poderpublico/sinapi/Paginas/default.aspx>. Acesso em: 18 abr. 2018.

CALDAS, L. R.; LIRA, J. S. de M. M.; SPOSTO, R. M. Avaliação do ciclo de vida de habitações de alvenaria estrutural de blocos cerâmicos e painéis pré-moldados de concreto considerando diferentes zonas bioclimáticas. LALCA -

Revista Latino-amer. em Aval. do Ciclo de Vida, Brasília, v. 1, n. 1, p. 138-167, jul./dez. 2017. DOI:

https://doi.org/10.18225/lalca.v1i1.3823

CARBONARI, L. T.; BARTH, F. Reutilização de contêineres padrão ISO na construção de edifícios comerciais no sul do Brasil. PARC Pesquisa em Arquitetura e Construção, v. 6, n. 4, p. 255-265, dez. 2015. DOI:

http://dx.doi.org/10.20396/parc.v6i4.8641165.

GARRIDO, L. Green container architecture. 1. ed. Barcelona: MONSA, v. 1, 2015.

HUMBERT et al. IMPACT 2002+: User Guide. Quantis, 2012. Disponível em: <https://www.quantisintl.com/pdf/IMPACT2002_UserGuide_for_VQ2.21.pdf> Acesso em 29 abr. 2019.

INVIDIATA, A., E.; GHISI, E. Impact of climate change on heating and cooling energy demand in houses in Brazil, Energy and Buildings, v. 130, p. 20-32, 2016. DOI: https://doi.org/10.1016/j.enbuild.2016.07.067 
ISLAM, H.; ZHANG, G.; SETUNGE, S.; BHUIYAN, M. A. Life cycle assessment of shipping container home: A sustainable construction. Energy and Buildings n.128, p. 673-685. 2016. DOI:

https://doi.org/10.1016/j.enbuild.2016.07.002

LabEEE - LABORATÓRIO DE EFICIÊNCIA ENERGÉTICA DE EDIFICAÇÕES. Arquivos Climáticos. Disponível em: <http://www.labeee.ufsc.br/> Acesso em 10. Jan. 2019.

LEVASSEUR, A.; LESAGE, P.; MARGNI, M.; DESCHÊNES, L.; SAMSON, R. Considering time in LCA: dynamic LCA and its application to global warming impact assessments. Environmental Science Technology, n. 44, p.3169-3174, 2010. DOI:https://doi.org/10.1016/j.destud. 10.1021/es9030003

LOPES, C. F. M. Análise do desempenho termo-energético de um edifício Residencial concebido a partir de container na cidade do Rio de Janeiro. 2016. 76f. Dissertação (Mestrado em Engenharia Urbana) - Centro de tecnologia, Universidade Federal do Rio de Janeiro, Rio de Janeiro, 2016.

LUNA, et al. Solar Photovoltaic Distributed Generation in Brazil: The Case of Resolution 482/2012. Energy Procedia, v. 159, p. 484-490, 2019. DOI: https://doi.org/10.1016/j.egypro.2018.12.036

MEDEIROS, L. M.; DURANTE, L. C.; CALLEJAS, I, J. A. Contribuição para a avaliação de ciclo de vida na quantificação de impactos ambientais de sistemas construtivos. Ambiente Construído, Porto Alegre, v. 18, n. 2, p. 365-385, abr./jun. 2018. DOI: http://dx.doi.org/10.1590/s1678-86212018000200259

MAURIELLO, M. J. This old shipping container. St. Louis Business Journal. News, Real State: A Quarterly Report. Abr. 2007. apud ISLAM, H.; ZHANG, G.; SETUNGE, S.; BHUIYAN, M. A. Life cycle assessment of shipping container home: A sustainable construction. Energy and Buildings n.128, p. 673-685. 2016.

DOI:https://doi.org/10.1016/j.enbuild.2016.07.002

PEREIRA, I. M.; ASSIS, E. S. Avaliação de Modelos de Índices Adaptativos Para Uso no Projeto Arquitetônico Bioclimático. Ambiente Construído, Porto Alegre, v. 10, n. 1, p. 31-51, jan./mar. 2010. DOI: http://dx.doi.org/10.1590/S1678-86212010000100002

PEREIRA, E.; SPOSTO, R. M.; CALDAS, L. R. Balanço de emissões de CO2 na exportação e importação do minério de ferro entre Brasil e China. In: CONGRESSO LUSO-BRASILEIRO DE MATERIAIS DE CONSTRUÇÃO SUSTENTÁVEIS, 2., João Pessoa. 2016. Anais [... ]. João Pessoa: CLBMCS, 2016, p. 8-19.

ROMANO, L; PARIS, S. de; NEUENFELDT JÚNIOR, A. L. Retrofit de contêineres na construção civil. Labor e Engenho, Campinas, SP, v. 8, n. 1, p. 83-92, fev. 2014. DOI: https://doi.org/10.20396/lobore.v8i1.225

SCHRIJVERS, D. L.; LOUBET, P.; SONNEMANN, G. Developing a systematic framework for consistent allocation in LCA. The International Journal of Life Cycle Assessment, July 2016, vol.21, n 1, p. 976-933. DOI: https://doi.org/10.1016/j.jclepro.2016.07.069

SILVA, M. G. da; GOMES, V.; SAADE, M. R. M. The contribution of life-cycle assessment to environmentally preferable concrete mix selection for breakwater applications. Ambiente Construído, Porto Alegre, v. 18, n. 2, p. 413-429, abr./jun. 2018. DOI: http://dx.doi.org/10.1590/s1678-86212018000200262

SOUZA, D. M., et al. Comparative life cycle assessment of ceramic brick, concrete brick and castin-place reinforced concrete exterior walls. Journal of Cleaner Production, v.137, n. 20, p. 70-82, jan. 2016. DOI: https://doi.org/10.1016/j.jclepro.2016.07.069

SONG, Y.; MITHRARATNE, N; ZHANG, H. Life-time performance of post-disaster temporary housing: A case study in Nanjing. Energy and Buildings, n. 128, p. 394-404, 2016. DOI: https://doi.org/10.1016/j.enbuild.2016.07.019

UN ENVIRONMENT AND INTERNATIONAL ENERGY AGENCY. Towards a zero-emission, efficient, and resilient buildings and construction sector: Global Status Report 2017. Geneva, Bangkok, Nairobi: UNEP, 2017. p. 43. 
CALDAS, Lucas Rosse; ABREU-HARBICH, Loyde Vieira de; HORA, Karla Emmanuela Ribeiro.

Avaliação ambiental de alternativas construtivas de um edifício contêiner

VIANA, F. S.; SOUZA, H. A. de; GOMES, A. P. Residência em contêiner: comparativo de estratégias para a melhoria do desempenho térmico. PARC Pesquisa em Arquitetura e Construção, Campinas, SP, v. 10, p. e019011, mar. 2019. DOI:https://doi.org/10.20396/parc.v10io.8652794.

WORLD SHIPPING COUNCIL. Containers. 2014. Acesso em: 15 abr. 2019.

WORLDSTEEL ASSOCIATION. Life Cycle assessment methodology report. Brussels: World Steel Association, 2011. Disponível em: https://www.worldsteel.org/en/dam/jcr:6a222ba2-e35a-4126-83ab-

5ae5a7ge6e46/LCA+Methodology+Report.pdf

\section{${ }^{1}$ Lucas Rosse Caldas}

Engenheiro Civil, Ambiental e Sanitarista. Doutor. Pesquisador no Núcleo de Ensino e Pesquisa em Materiais e Tecnologias de Baixo Impacto Ambiental na Construção Sustentável (NUMATS/COPPE/UFRJ). Universidade Federal do Rio de Janeiro, Centro de Tecnologia (CT), Ilha do Fundão, Rio de Janeiro, RJ, Brasil, CEP: 21945-970.

\section{${ }^{2}$ Loyde Vieira de Abreu-Harbich}

Arquiteta e Urbanista. Doutora. Professora Pesquisadora da Faculdade de Arquitetura e Urbanismo da Universidade Presbiteriana Mackenzie (UPM) e colaboradora do Programa de Pós-Graduação Projeto e Cidade (PPG-PC-FAV da UFG). Universidade Presbiteriana Mackenzie, Faculdade de Arquitetura e Urbanismo, Edifício Cristiano Stockler das Neves Rua Itambé, 143 - Prédio 9, Higienópolis, São Paulo. Brasil, SP CEP: 01302-907.

\section{Karla Emmanuela Ribeiro Hora}

Arquiteta e Urbanista. Doutora. Professora Associada na Escola de Engenharia Civil e Ambiental da Universidade Federal de Goiás e dos Programas de Pós-Graduação Projeto e Cidade (PPG-PC-FAV da UFG) e Ciências Ambientais (PPG-CIAMB da UFG). Universidade Federal de Goiás, Escola de Engenharia Civil, Praça Universitária, s/n, Bloco A, sala 12, St. Universitário, Goiânia, Goiás, Brasil, 74605220. 